\title{
Study on How to Improve Engineering Student's Ability to Solve Complex Engineering Problems
}

\author{
Xianming $\mathrm{Li}^{*}$ and Hongru $\mathrm{Li}$ \\ School of Control Science and Engineering, Shandong University, Jinan, China \\ ${ }^{*}$ Corresponding author
}

\begin{abstract}
New approaches to improve engineering student's ability to solve complex engineering problems have been studied. The student's ability of "practice combine with theory" is very necessary for them to solve complex engineering problems. Taking the automation specialty of Shandong University as an example, the approaches to improve the student's ability of "practice combine with theory" have been given.
\end{abstract}

Keywords-engineering education; automation specialty; practice; theory

\section{INTRODUCTION}

The International Engineering Education Alliance "Washington Accord" places special emphasis on student's ability to analyze and solve complex engineering problems. There are 12 graduation requirements for Chinese Engineering Education Professional Certification Standards and "complex engineering problems" are clearly indicated in eight of them and their main characteristics have been defined ${ }^{[1]}$. For example, it must be analyzed using in-depth engineering principles before it can be solved and requirements involve various technical and engineering factors, and they may have some conflicts with each other.

Contrary to the certification requirements for engineering education, the reality is not optimistic. Take the automation specialty of Shandong University as an example to explain as follows. The basic forms we teach students are classroom teaching and course experiments. Many courses, such as mathematics, physics, circuits, electromagnetic fields, digital and analog electronics, automatic control principle, electric motor and electric drive, power electronics, and so on, were given to students. However, the common problem is that once students encounter practical problems that can be resolved with knowledge they have learned, it is very difficult to establish links between the actual problems that need to be solved and the knowledge needed. So to solve the problems especially "complex engineering problems" become very difficult. The primary reason for our graduates lack the ability to solve complex engineering problems is the lack of the ability to link the complex engineering problems they face with the theoretical knowledge they have already learned.

\section{The Source of THE PROBLEM}

Over the years, Chinese have become accustomed to the phrase "theory combine with practice." It has almost become a Chinese idiom. However, the process of resolving practical problems is counter-intuitive, that is the process of "practice combine with theory". The students lack the ability of "practice combine with theory" and the ability to solve complex engineering problems is greatly limited.

Why do our graduates lack the ability of "practice combine with theory”? The main reasons may be:

\section{A. Teacher's Lectures}

Some teacher's lectures are less involved in practical problems. Even if actual problems are involved, they are often used to illustrate and verify "theory" simply. "Practice" has become an addendum to "theory" in the lectures.

\section{B. Textbooks}

Examples and exercises are too simplistic and lack practical background in some Chinese textbooks. At this point, some international textbooks do better in which many of the examples and exercises have obvious practical background.

\section{Experiments}

Experiments are mostly simple verification experiments. It seems that the purpose of the experiment is only to learn "theory" and verify "theory."

\section{Declining Quality of Production Practice}

Production practice is an indispensable teaching link in undergraduate teaching of engineering majors. It is an effective way to cultivate student's practical ability to analyze and solve problems. According to our teaching tradition, students are required to go deep into the production line of state-owned large or medium-sized enterprises, and they live and work together with workers and technicians. However, the large and medium-sized state-owned enterprises have now entered the market economy mode entirely from the planned economy mode. In addition, the number of students has increased due to the expansion of enrollment in universities. These have led companies to change their "welcome" to "cool" or even "contradictory" with students. The opportunities for production internships are getting harder and harder. So the teaching quality is significantly reduced.

\section{E. Declining Quality of Graduation Design}

Graduation design would have been able to better train student's ability to "connect theory with practice". However, in recent years, students have not been well-studied at the course. They spent a lot of time looking for jobs everywhere and participating in postgraduate enrollment retests or preparing for overseas English exams. So the quality of graduation design has declined significantly. 


\section{PROBLEM SOLUTION}

\section{A. Classroom Teaching, Examples and Exercises}

Before the teacher talks about a "theory," it is best to first explain the actual background of the "theory" and to derive the necessity of the "theory" from "reality." For some practical examples of this "theory," teachers can wait until the student's memory of this "theory" is somewhat vague to explain the example, instead of talking about "theory" followed by the "real" example. In this way, students can develop the ability and habits of recalling and linking "theory" from practical problems. The author once encountered a practical problem of a motor speed control system in a company and the fault phenomenon was very much like electromagnetic interference. After painstaking and meticulous investigation, it was finally confirmed that the malfunction was caused by tiny foreign matter inside the encoder. The author explained this example two weeks after the instruction of the encoder course and the effect would be much better. Many students still remember the example at their graduation of the 10th anniversary.

Examples and exercises may be selected based their actual backgrounds and may be utilized from some international textbooks.

\section{B. Course Experiments}

More comprehensive and innovative experiments would be designed. An actual micro beer production line has been designed as the object controlled and several comprehensive, design and innovative experiments have been developed by the authors. So student's initiative and creativity were fully stimulated and students' engineering awareness and quality has been cultivated.

\section{Production Practice}

In the second or third semester, a one-week cognitive training session may be set up. Through the course, students can have a deep understanding of the characteristics of the automation specialty and be familiar with the automation engineers in the actual production environment to lay solid foundation for the study of follow-up courses and establish engineering concepts early. So classroom teaching would be linked to reality easily.

In order to make up the lack of off-campus production internships, the automation specialty practice base on-campus has been established based on Shandong University engineering training center. The organic combination of on-campus and off-campus internships can accomplish the task of production internships better.

\section{Graduation Design}

Graduation design should start from "the problem to be solve" and end up with "the problem solution". It is the "live-fired drill" before the students go to work. The main purpose of graduation design is to enable students to master the general procedures and methods of engineering design, and to strengthen student's ability to use the knowledge they have learned to solve practical problems and to think independently. Graduation design is a comprehensive training to improve the student's ability of "practice combine with theory".
The topics selected for the graduation project must meet the professional training objectives, the international professional certification standards and meet the national standards and specifications for the training of high-level professionals in institutions of higher learning. As far as possible, the topic would be selected from the needs of the enterprises. This kind of topic is more challenging and practical. Instructors should fully understand the student's working conditions, guide students to collect and read references and materials, select design plans and technical routes, and do a good job of guiding key links. They should carefully examine design methods and theoretical analysis, data processing, and conclusions. Instructors should pay attention to the cultivation of student's abilities and the guidance of design ideas and methods. They should strictly meet the requirements of students and be rigorously trained so that students can learn to analyze and solve problems independently. The instructor should pay attention to mobilize the enthusiasm and creativity of students and guide students to correctly write graduation design paper.

\section{E. Choosing the Appropriate Control Object and Establishing Workshops for Students ${ }^{[2][3]}$}

Most of the experimental devices produced specifically for teaching experiments have the characteristics of simplification and simulation, and there is a large gap between the actual industrial production and the actual production. We have found a good method that choosing a miniature but still practical production process as the controlled object establishes a workshop for automation professionals, allowing students to carry out automatic detection and automatic control on their own in light of practical problems. This can cultivate the ability to "connect theory with practice" of students.

\section{1) Biological fermentation process control workshop:}

The parameter detection, automatic control, process monitoring, and process optimization in the fermentation process have become bottlenecks in the fermentation process. The establishment of experimental equipment using the fermentation process as a controlled process can highlight the important role of automation technology. The miniature beer production line were chosen as the controlled object. The beer production process mainly includes malt powder, saccharification, filtration and precipitation, cooling by heat exchanger, pre-fermentation and post-fermentation. The main equipment include a saccharification boiling tank and a filter sedimentation tank, six fermentation tanks, one ice water tank, one refrigeration unit, and one plate heat exchanger, etc. The requirements for automatic measurement and control include: temperature and liquid level of the saccharification and boiling tank; the filter sedimentation tank; the heat exchange process of the heat exchanger; the temperature, pressure, flow, liquid level, sugar content, PH value, alcohol content, dissolved oxygen concentration, yeast concentration and other parameters of the 6 fermentation tanks; temperature, flow of ice water tank; five motor control of saccharification pumps, pipeline pumps, cultivators, agitation, refrigeration machine. The required multiple sensor mounting holes on the controlled object were customized and the leads of various actuators were led such as electric heating tubes, motors, and solenoid 
valves to a dedicated wiring board. The required sensors and controllers were provided to make up the device library, so a "workshop" for automated professional micro beer production lines was formed. For example, some projects based the workshop may be:

a) temperature control system for beer production saccharification process and the temperature control system for beer fermentation process.

b) feedforward and cascade control system for wort inoculation process.

The main equipment of the biological fermentation process control workshop is shown in Figure I.

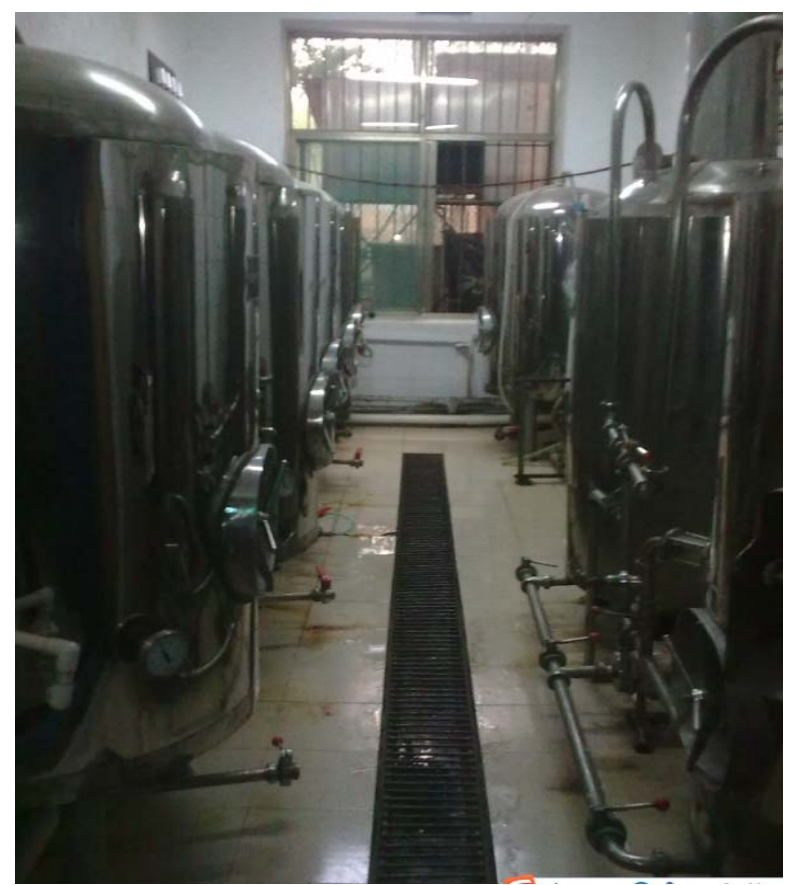

FIGURE I. MAIN EQUIPMENT IN BIOLOGICAL FERMENTATION PROCESS CONTROL WORKSHOP

2) Inverter welding equipment workshop:

Automation major has the essential characteristics of interdisciplinary. By the end of the sixth semester of the undergraduate degree, the major core courses of the automation major have been completed. Since most students lack the ability to integrate the knowledge of each course, a number of "isolated islands of knowledge" were formed in their minds. Therefore, it is imperative to provide students with a practical platform that can deepen understanding and comprehensively apply the learned knowledge, and establish "bridges" between "independent islands of knowledge" to help students establish a complete and organic knowledge system. The design principles of the practice platform are proposed:

a) The core of the platform must be a true system that functions in actual industrial production;

b) The core of the platform must be an autonomous control system with independent functions;

c) The core of the platform must cover the major core courses of the undergraduate major in automation.
The inverter welding machine was selected as the core of the practical platform. The main basis is as follows:

a) The welder is an actual device that plays a role in industrial production.

b) Inverter welder is an automatic control system with practical welding functions. Its control object is an arc, with enough complexity, but it is not a monster like a kiln or a reaction tower.

c) Inverter welding machine is a typical power electronic product, and its internal technical elements include the main courses learned by the students of automation major in the first three years.

Many projects can be realized on the platform such as system modeling, analysis, design, debugging and operation. The projects have been implemented successfully for four years in Shandong University. The main equipment of the inverter welding equipment workshop is shown in Figure II.

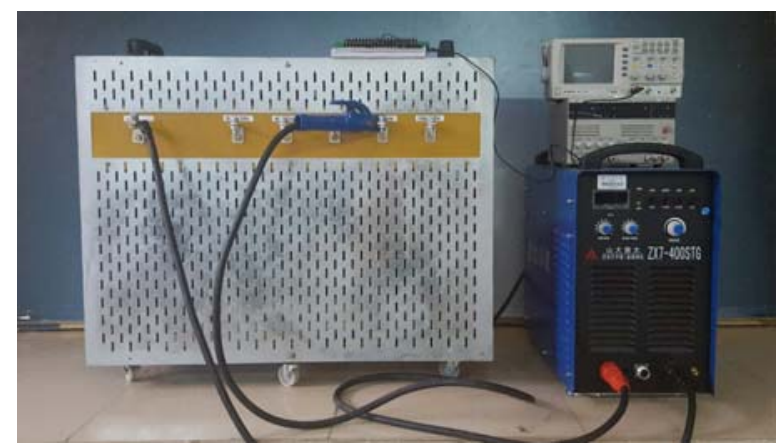

FIGURE II. MAIN EQUIPMENT IN INVERTER WELDING EQUIPMENT WORKSHOP

\section{CONCLUSION}

The focus is "theory" in "theory combine with practice" and the focus is "practice" in "practice combine with theory". "Theory combine with practice" and " practice combine with theory" are complementary to each other. For the scientific and technical personnel who are engaged in theoretical research, they should abide by the principle of "Theory combine with practice"; for those engineers who are engaged in practical technical work, they should focus on training the ability of "practice combine with theory". For the teachers of engineering students, they should work hard in classroom teaching, examples, exercises, experiments, internships, workshops, etc., to cultivate student's abilities and habits of "practice combine with theory", and to improve student's ability to solve complex problems so that students can meet the needs of employers.

\section{REFERENCES}

[1] Lin Jian. Training of Outstanding Engineers - Systematic Reform of Engineering Education [M]. Beijing: Tsinghua University Press, 2013.

[2] Svante Gunnarsson et al. Automatic Control Education in a CDIO Perspective. IFAC PapersOnLine 50-1 (2017) 12161-12166.

[3] Roman M. Luchin et al. Improving control engineering education with TRIK cybernetic system. IFAC PapersOnLine 50-1 (2017) 15716-15721. 